\title{
POR LAS RUTAS DEL QHAPAQ ÑAN: EI ROL DE LOS CAMINOS EN LA CONSTRUCCIÓN DE LA HISTORIA Y TERRITORIO PERUANO'
}

\author{
BY THE ROUTES OF QHAPAQ NAN: THE ROLE OF THE ROADS IN THE \\ CONSTRUCTION OF THE PERUVIAN HISTORY AND TERRITORY
}

\begin{abstract}
Giancarlo Marcone ${ }^{2}$
La historia oficial peruana plantea que el cambio del periodo Prehispánico al Colonial fue tan profundo que reestructuró el espacio andino; sin embargo, la experiencia nos indica que existe una continuidad en el uso de los caminos por los diversos actores que pasan y/o habitan el territorio peruano. En este artículo cuestionamos ¿cómo es posible la sobrevivencia y uso del camino si se supone que cuando los Incas cayeron se derrumbó con ellos su sistema administrativo y por ende su sistema vial? y ¿cuánto de la organización geopolítica y social del Perú colonial y luego del Perú contemporáneo pueden ser explicadas a partir del camino prehispánico? Estas preguntas las abordamos desde una perspectiva de territorio, paisaje y movimiento, los cuales brindan una visión temporal mayor y una escala espacial más amplia. Además, fijándonos en la variación de algunas rutas y trazos, realizamos un análisis diacrónico que nos permite entender la relación de cambio y continuidad que existió a través de la historia en el territorio peruano para, posteriormente, discutir los impactos que ha tenido la construcción de la historia peruana dándole más peso a los cambios que a las continuidades.
\end{abstract}

Palabras claves: Qhapaq Ñan, Movimiento, Territorio, Ruta, Camino Inca, Continuidad y Cambio

According to official Peruvian history, the change from the Prehispanic to the colonial period was so profound that it restructured the Andean space; nevertheless, experience shows that the roads have continued to be used by the various actors that make use of and/or inhabit the Peruvian territory. In this article, we question how it is possible that the roads have survived and continued to be used after the collapse of the Inca administrative system, and therefore their road system as well, and how much of the geopolitical and social organization of colonial Peru, and then of contemporary Peru, can be explained from the Prehispanic road. We have approached these questions from a perspective of territory, landscape, and movement, which provides a greater temporal vision and a wider spatial scale. Furthermore, observation of variations in some routes and traces has allowed us to carry out a diachronic analysis to understand the relationship between change and continuity present throughout the history of the Peruvian territory, and to discuss the impacts of the construction of a Peruvian history that has focused more on changes than continuities.

Key words: Qhapaq Ñan, Movement, Territory, Route, Inca Road, Continuity and change.

De hecho, las etnografías de caminos permiten al etnógrafo desentrañar las prácticas e imaginarios que funcionan a través de las escalas, por ende a través de características sociológicas tradicionales: desde la materialidad a los sujetos humanos, del Estado a la sociedad y de allí a los individuos (Dalakoglou y Harvey 2012:460).

Durante los años 2012 y 2013, existía un proyecto de inversión pública para asfaltar un tramo de camino de trocha que comunicaba a dos comunidades de la zona de Huachis, en el departamento de Ancash, Perú. El proyecto contaba con presupuesto y respaldo tanto de la municipalidad local como del organismo del Gobierno Central que se encarga de realizar este tipo de obras (Provias Descentralizado). Al momento de pedir las autorizaciones respectivas al Ministerio de Cultura del Perú para empezar la obra, se puso de manifiesto que el origen de este camino de trocha era prehispánico.

\footnotetext{
${ }^{1}$ Una primera versión de este trabajo fue presentada en el Qhapaq Ñan II, Taller Internacional en torno al Sistema Vial Inkaico (24-27 de octubre de 2017), efectuado en Salta, Argentina. Este manuscrito fue evaluado por pares externos y editado por el Comité Editorial de Chungara y los editores invitados Carlos González y Christian Vitry.

${ }^{2}$ Centro de Impacto y Responsabilidad Social (CIRSO), Universidad de Ingeniería y Tecnología, Lima, Perú. gmarcone@utec.edu.pe
} 
Una tarea que tuvo que afrontar el Proyecto Qhapaq Nan-Sede Nacional fue la de detener esta obra dado que el segmento de camino que querían asfaltar era una sección de Camino Inca que, además, era parte del expediente preparado para la declaratoria del Qhapaq Ñan como patrimonio mundial ante UNESCO. Durante los meses que llevó la negociación con los organismos respectivos -quienes en todo momento buscaron respetar el trazo del Camino Inca- entendí que el Qhapaq Ñan todavía está en uso y está lleno de significados para los pobladores que viven alrededor de él. Experiencias similares, en las que tramos del Qhapaq Ñan entran en conflicto con carreteras modernas, podemos encontrarlas en otras áreas del Perú.
Por ejemplo, en Huachón, el Gobierno Regional de Pasco impulsó la construcción de una carretera que destruyó parcialmente el camino. En el Valle de Cañete, región Lima, la construcción de una carretera moderna afectó el Camino Inca transversal que bajaba por ese valle. Inclusive, cerca de Lima, en la zona de Asia, encontramos evidencia de la Carretera Panamericana disturbando remanentes del camino costero (Figura 1).

Esto me llevó a plantear una serie de preguntas. ¿Cómo es posible esta continuidad de uso en los caminos si la historia oficial plantea que el cambio de prehispánico a colonial fue tan profundo que reestructuró el espacio andino? ¿Cómo es posible la sobrevivencia y uso del

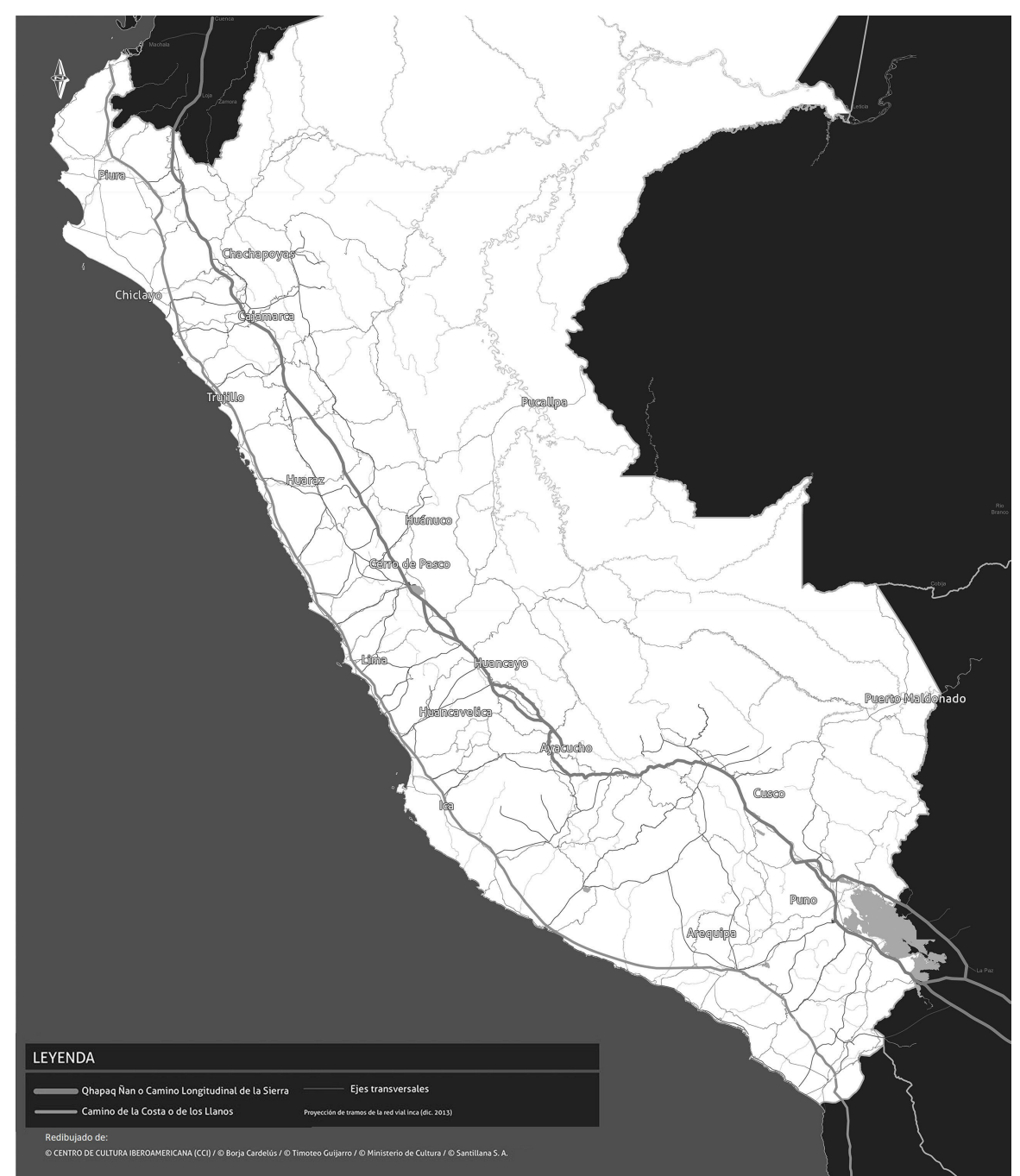

Figura 1. Mapa del Qhapaq Ñan en el Perú, se detalla el camino longitudinal de la Sierra, el camino de la Costa y los ejes transversales. También se indican las carreteras actuales y principales. Redibujado de Centro de Cultura Iberoamericana (CCI)/ Borja Cardelús/Timoteo Guijarro/Ministerio de Cultura/Santillana S.A.

Map of Qhapaq Nan in Peru, detailing the longitudinal path of the Sierra, the Coastal path, and the transversal axes. The current and main roads are also indicated. Redrawn from Centro de Cultura Iberoamericana (CCI)/ Borja Cardelús/Timoteo Guijarro/Ministerio de Cultura/Santillana S.A. 
camino si se supone que cuando los Incas cayeron se derrumbó con ellos su sistema administrativo y por ende su sistema vial? Y finalmente, ¿Cuánto de la organización geopolítica y social del Perú colonial y luego del Perú contemporáneo pueden ser explicadas a partir del camino prehispánico? En otras palabras, ¿Cuál es el impacto que la historia prehispánica (luego colonial y republicana) dejó en las maneras como se relaciona nuestra sociedad con su paisaje? ¿Es el paisaje y sus transformaciones culturales (como por ejemplo los caminos) un elemento activo en la construcción de nuestra historia?

La investigación de los caminos ha estado implícitamente centrada en entenderlos como una obra de infraestructura que fue construida por entidades centralizadas -como Estados e Imperios-, o como resultado de la acción diaria de la gente que lo usa y mantiene (Garrido 2016; Garrido y Salazar 2017). En el primer grupo se priorizan las funciones administrativas y adaptativas del camino, mientras que en el segundo se afianza la idea de vida diaria y de los posibles significados simbólicos y culturales que tiene como expresión de la interacción del hombre con la naturaleza y medio ambiente (Garrido 2016). Esta es una falsa dicotomía, ya que los caminos constituyen un enlace entre la práctica diaria (quienes usan el camino y lo mantienen) y las estructuras sociales y políticas (las entidades centralizados que los construyen, planifican e intentan controlar) (Dalakoglou y Harvey 2012). Estas prácticas sociales diarias, al igual que las practicas impuestas por el Estado o la organización política superior, son una compleja red de variables económicas, sociales, políticas y también ideológicas, que se negocian y reformulan en todo momento entre el individuo y su sociedad.

El presente ensayo pretende discutir el Qhapaq Ñan o Camino Inca desde una perspectiva de territorio, paisaje y movimiento, las cuales nos brindan una visión temporal mayor y una escala espacial amplia. Buscamos mostrar como el camino es efectivamente el enlace entre procesos sociales que usualmente se conceptualizan como separados, por ejemplo, ideología estatal (en el sentido general de un modelo organizativo social que se impone desde el Estado y que incluye aspectos económicos, sociales, políticos y netamente ideológicos), y la agencia y práctica cotidiana. Esta práctica cotidiana le permitió al camino sobrevivir parcialmente los cambios políticos sucedidos después de 1531 y dejar su impronta en las trasformaciones sociales coloniales y posteriormente republicanas. Los caminos son formados por las sociedades y a la vez forman nuestras sociedades. Desde esta perspectiva, es posible afirmar que los caminos son también un enlace entre el pasado y el presente del territorio.

Si bien este estudio se encuentra aún a nivel de propuesta y los ejemplos usados son muy generales, pensamos que ilustran a cabalidad el potencial que tiene el pensar el Qhapaq Ñan desde la perspectiva de territorio, donde analizamos la continuidad en algunas rutas y trazos del camino a manera de ejemplo, buscando entender cómo estos cambios o continuidades fueron parte de un intrincado proceso cultural y social. Es en estos intricados procesos donde las cosmovisiones andinas, la de los primeros conquistadores y posteriormente la republicana se encuentran, conflictúan y, finalmente, se negocian con las concepciones y significados locales. Pensamos que este análisis de la infraestructura vial en visión diacrónica nos permite acercarnos a entender la compleja relación de cambio y continuidad que existió a través de la historia en el territorio peruano, para posteriormente discutir los impactos negativos y excluyentes que tuvo el construir la historia peruana dándole más peso a los cambios que a las continuidades.

Los caminos no son la única expresión de construcciones prehispánicas que trasformaron el paisaje e influyeron en los posteriores desarrollos políticos, manteniendo su presencia desde tiempo pre-hispánicos y que, de alguna manera, son usados en nuestros días, aunque con distintos significados. Por ejemplo, terrazas o andenes agrícolas han sobrevivido en el paisaje, aunque sus funciones puedan haber cambiado (Delgado 2019; Traecy 1994). Por ejemplo, Wernke (2013) hace un punto similar sobre linderos y marcadores de propiedad que juegan un rol de base para un proceso de negociación por parte de los pobladores locales con las nuevas autoridades españolas, donde el resultado es fruto de este intercambio entre ellos, pero siempre en referencia a los linderos ya preestablecidos. O el estudio de Chacaltana y Cogorno (2018) sobre el sistema de irrigación prehispánica que jugó un rol en el planeamiento de la ciudad de Lima y que aun ahora existe dentro de la ciudad. Con esto no queremos implicar que estos elementos del paisaje sobreviven como "instituciones", sino que las instituciones se reformulan y transforman sobre la trasformación material que estas obras dejaron sobre el paisaje. Van Valkenburgh (2017: 117-118) señala la necesidad de entender la materialidad del paisaje para poder entender el proceso de formación de súbditos y el establecimiento de la política colonial.

\section{Territorio: Paisaje y Movimiento}

Nuestra pregunta inicial - ¿Cómo es posible esta continuidad de uso en los caminos si la historia oficial plantea que el cambio de prehispánico a colonial fue tan profundo que reestructuró el espacio andino? - solo puede ser contestada desde la perspectiva de territorio, en la cual este no solo está presente, sino activo en la producción y reproducción social.

El territorio es el espacio geográfico-entendido como marco de vida- donde, en un espacio de construcciones políticas, económicas y sociales, la interacción entre individuos y grupos define un sentido de pertenencia y reconocimiento como conjunto (Altschuler 2013; González Navarro 2012). Este no es solo un fenómeno 
en términos físicos, sino también implica la concepción del espacio en términos ideológicos (González Navarro 2012; Pino 2017), lo que implica que las realidades físicas (las formas que vemos), históricas y culturales (memoria y experiencia) son concéntricas y que las sociedades son resultado de la convivencia e interacción de las mismas. El territorio no es estático, puede cambiar por factores ambientales, económicos, políticos o sociales, redefiniendo su composición (González Navarro 2012).

El paisaje es la materialización de este territorio. Las improntas que deja el hombre en el paisaje estarán directamente vinculadas a sus concepciones del territorio y a las trasformaciones que esta concepción sufre (Vitry 2007a). Por ejemplo, los caminos son usados para unir comunidades o separarlas, para reconocer unidades territoriales, para definir límites entre grupos o justamente cuestionarlos, entre otros usos sociales y culturales.

En resumen, podemos afirmar que el paisaje refleja el territorio, el cual es fruto de las cosmovisiones, ideologías políticas y económicas de los grupos que desarrollan su territorialidad (Ashmore 2015; Snead et al. 2009). Los cambios en estas cosmovisiones e ideologías (entendiéndolas en el sentido general de un modelo organizativo que incluye aspectos económicos, sociales, políticos y netamente ideológicos) necesariamente traerán cambios en los principales "marcadores" del paisaje, por ejemplo, los caminos y otras obras de infraestructura (Larkin 2013). Sin embargo, este nuevo paisaje no será formalizado hasta que los elementos o marcadores del paisaje -como son los caminosentren en la cotidianidad de los actores, legitimando y fomentando la práctica de los nuevos contenidos culturales (Ashmore 2015). Entonces, dentro de esta dinámica resulta lógico que con el paulatino surgimiento de estudios que específicamente toman un marco conceptual en el territorio y el paisaje, también hayan aumentado los estudios sobre movilidad y por ende de los caminos (Dalakoglou y Harvey 2012:462).

\section{Caminos: Movimiento, Política y Cosmovisiones}

Como mencionábamos, el territorio y el paisaje son la materialización de cosmovisiones e ideologías (que dan forma a las diversas estrategias políticas, sociales y económicas), y el movimiento a través de ellos es una suerte de toma de posesión de este paisaje (Ashmore 2015:293). El movimiento y el uso del camino fortalecen la memoria, por lo que su cambio está ligado a lo que determinada sociedad busca recordar o transformar (Ashmore 2015; Snead et al. 2009). El movimiento reproduce en el paisaje las cosmovisiones de los pobladores, pero también las ideologías estatales impulsadas conscientemente desde las autoridades políticas (Ashmore 2015; Larkin 2013; Snead et al. 2009). Lo que en palabras de Carlos González podríamos llamar la "narrativa social" de las sociedades (González Godoy 2017:20) que se crea o mantiene en base al movimiento por los caminos y que incluye desde contenidos adaptativos y tecnológicos hasta espacios ideológicos y manifestaciones simbólicas de poder.

Los caminos, dentro de este marco conceptual de territorio, no son solo el enlace entre lo regional y lo local o entre la práctica diaria y la economía política estatal, también son un enlace temporal entre sociedades que, diacrónicamente, comparten un mismo territorio (Ashmore 2015; Dalakoglu y Harvey 2012; Larkin 2013:328; Masquelier 2002:832). El camino es la expresión máxima de la transformación del paisaje por acción del hombre, estas transformaciones en el paisaje generan marcas (los trazos del camino) sobre las que se generan las siguientes transformaciones del paisaje (Ruiz et al. 2015:45-46). Las sociedades que actúan sobre el mismo territorio tienen que lidiar con las transformaciones del paisaje anteriores a ellas. Es así que los caminos (como otras obras de infraestructura) terminan funcionando como marcadores paisajísticos y su efecto transformativo del paisaje no es estático sino dinámico, es parte de un proceso permanente de construcción del territorio y de sistemas culturales (Larkin 2013; Ruiz et al. 2015:45). Los caminos son construidos por la sociedad y a la vez forman las sociedades.

El estudio de los caminos a nivel mundial muestra que estos tienden a construirse sobre las rutas previas siempre y cuando nuevas cosmovisiones, ideologías estatales, adelantos técnicos, cambios de vehículos u otros contenidos culturales no justifiquen su abandono (Ruiz et al. 2015:48-49). La supervivencia de las rutas previas es muestra del proceso acumulativo de la historia de las sociedades. Las transformaciones y adecuaciones de rutas más recientes sobre las antiguas evidencian los ajustes necesarios a la ruta para adecuarlas a los nuevos significados culturales y sociales, incluso políticos (Larkin 2013; Ruiz et al. 2015).

Los Andes no tienen por qué ser la excepción. Sin embargo, la historiografía tradicional ha presentado el momento de la conquista española como un choque de civilizaciones, idea que sigue siendo influyente hasta el presente (Lamana 2008:3), aunque con distintos grados de reconocimiento de la agencia indígena. Este choque significó, para algunos autores, un quiebre fundamental en las esferas sociales, culturales y políticas (Lumbreras 1990:24) y vino acompañado con la desestructuración del mundo andino (Watchel 1976), la "devastación" del orden andino (Murra 2002:9), inclusive con la creación de nuevos territorios (Martínez 2009:29). En el caso del Camino Inca, estas propuestas de choque de civilizaciones se vieron reflejadas en términos de "abandono", "destrucción” o "fin abrupto" (Martínez 2009:29-30), "pérdida" (Martinez y Murrillo 2015:13), "olvido" (Cardelus y Guijarro 2013:6) -solo para poner algunos ejemplos- de la red vial a la caída del 
Imperio Incaico, contribuyendo a invisibilizar procesos y contenidos locales adjudicándole al Estado Inca toda la agencia sobre los caminos. Inclusive invisibilizando que a su vez algunos de estos caminos son de origen anterior a los mismos Incas (Martínez 2009:22).

En estas visiones el paisaje es un ente neutro. Las transformaciones realizadas por los Incas y los 5.000 años de historia anteriores a ellos en el paisaje no jugaron un rol en estructurar las formas sociales y políticas desarrolladas durante la colonia y la república en el Perú, sino que perdieron significado cultural, conceptualizándolos como sincretismos sobrevivientes. Adicionalmente, el riesgo es que en esta visión cataclísmica del territorio prehispánico negamos, por principio, el rol y la importancia de la acción cotidiana sobre el paisaje y los caminos, priorizando la acción de Estados y sistemas políticos sobre los contenidos culturales de estos caminos en la arena local; finalmente, llevando a la invisibilización del poblador local de la historia peruana. Estas tendencias a priorizar la idea de quiebre cultural continuaron hasta que en los últimos años conceptos como paisaje y territorio son incorporados a los planteamientos arqueológicos e históricos (Acuto 2012; Christie 2008; Farrington 1992; Julien 2012; Kaulicke et al. 2003; Kosiba y Bauer 2013). Por ejemplo, en el caso del Camino Inca basta con mirar el volumen "Nuevas tendencias en el estudio de los caminos" (Chacaltana et al. 2017).

El pensar el camino (y la historia en general) desde esta perspectiva territorial y de continuidad histórica nos ayuda a mirar los procesos históricos sociales de una manera sostenida y nos lleva a cuestionar nuestros constructos históricos tradicionales, cuestionar cómo hemos pensado la historiografía clásica del Perú minimizando lo local en parte de nuestros procesos históricos.

\section{Trazo y Ruta}

Para fines de este estudio podemos definir dos elementos principales a la hora de planificar, construir o estudiar un camino. El primer elemento a considerar es el "trazo" del camino. El trazo está referido a la manera como se construye el camino una vez que la ruta está definida. Este es reflejo de condiciones técnicas, tecnológicas y económicas que facilitan y posibilitan determinado tipo de camino; además, se ajusta a determinado tipo de vehículo, así como a nuevos significados culturales y simbólicos. El trazo puede variar, aunque la ruta en sí no haya variado mayormente o de acuerdo a las expectativas de la gente sobre el camino y su importancia como símbolo de poder. Inclusive, en un mismo periodo una misma sociedad puede construir caminos que varían en forma, tecnología y monumentalidad (Ruiz et al. 2015:50).

Entonces, el trazo también se ve afectado por cambios culturales y el arribo de nuevas cosmovisiones -es decir- nuevas ideologías, pero también nuevas formas de producción, redistribución y comunicación. Por ejemplo, Guido Casaverde (2017) ha documento varios ejemplos donde el Camino Inca es adaptado, reduciéndole la pendiente y/o ampliándole las curvas para que sea usable por caballos y animales de tiro introducidos por los españoles sin necesidad de variar la ruta. Si la ruta no muestra mayor variación de una sociedad a otra o las características naturales y culturales del paisaje no permiten fáciles variaciones, el nuevo trazo tenderá a respetar el trazo anterior. Aunque las características tecnológicas del camino, su propiedad y uso puedan transformarse en función a cambios culturales mayores.

Un segundo elemento es el que identificamos como la ruta. La ruta es el resultado de una necesidad de comunicación entre dos o más puntos. Esta necesidad no siempre es estrictamente funcional o económica, sino que se va a ajustar a la percepción de territorio y a la necesidad de intervenir el paisaje para reafirmar o cuestionar el mismo (González 2017; Larkin 2013). En geografías accidentadas, como la andina, no solo es importante los lugares de destino para el establecimiento de la ruta, sino que es de especial relevancia los pasos angostos o los pasos obligados por donde cruzar la cordillera o por donde atravesar determinado río para la determinación de una ruta. Así, la ruta no solo está dominada por el destino, sino también estará relacionada a las específicas características geográficas que limitan o dificultan el movimiento y traslado. Lo que significaría que el paisaje tiene una fuerte influencia en la planificación de la ruta.

Para este estudio nos concentramos principalmente en la permanencia o cambio de las rutas. En específico, miraremos dónde se produce el cambio y transformaciones de las rutas y ejes de movimiento en el territorio del área andina que incluyen al Perú actual, a través del tiempo y de los cambios socio-políticos.

Algunas ideas base que, a riesgo de parecer obvias, valen la pena discutirlas explícitamente, ya que sustentan en parte el presente argumento. La permanencia de una ruta o tramo del camino entre dos sitios de los ejes de movimiento, que sobreviven a pesar de los cambios en las cosmovisiones, puede reflejar tres cosas: (1) una fuerte influencia del paisaje en la planificación de la ruta; (2) una larga tradición cultural acumulativa de rutas a través del tiempo (Ruiz et al. 2015: 52) que complica la variación; (3) una relativa similitud entre las cosmovisiones y/o ideologías estatales que no justificarían la inversión en un cambio. Estas tres opciones no son excluyentes, sino más bien complementarias y ayudan a entender la continuidad en el paisaje.

Los cambios de rutas, en tanto, sucederían cuando el mantenimiento de la ruta anterior careciera de sentido, ya sea en términos económicos o culturales. Para esta discusión asumimos que, cuando es posible, las nuevas instituciones políticas van a preferir construir los caminos siguiendo las rutas anteriormente establecidas y que ya tienen la validación del uso diario de la gente. 
Entonces, el cambio en la ruta implicaría dos cosas: (1) la pérdida del uso cotidiano y/o significado a nivel local, o (2) que este cambio es explícitamente necesario para el establecimiento de una ideología y/o economía política estatal o cosmovisión determinada, dejando la arena local en segundo plano.

\section{La continuidad de las rutas}

En Los Andes peruanos encontramos ejemplos de todas estas situaciones. Existe la pervivencia de rutas, como en el caso del tramo de Vilcashuamán (Ayacucho) a la Centinela (Ica) que claramente fue adoptado por los españoles, inclusive desde la época más temprana de la presencia europea en el Perú, convirtiéndose en una vía principal entre Lima y Cusco, alterando las dinámicas locales y fomentando la despoblación de la región (Figura 2) (Barraza 2013:3). Este camino fue construido al terminar la primera etapa de expansión Inca, cuando traspasaron las barreras de la región Cusco y comenzaron a tener una proyección transregional.

Las evidencias arqueológicas indican que Vilcashuamán constituyó un centro importante en la Red Vial Inca (Wernke et al. 2017) donde confluía tanto el Qhapaq Ñan de la sierra como el camino transversal que llevaba a los poderosos reinos costeños de Ica y Chincha. A lo largo de este camino encontramos sitios de filiación Inca que presentan una fina mampostería, solo comparable con la arquitectura imperial (Figura 3). Alrededor de los sitios, además de estar relacionados directamente con el agua, los Incas construyeron un gran sistema de andenería. La relación entre andenería, manejo del agua y fina mampostería Inca nos hace pensar que estos podrían corresponder a palacios de una nobleza Inca en expansión que buscaba acumular riqueza y poder. Un planteamiento similar al que hace Catherine Julien para los sitios Incas que identifica en el tramo del camino del Chinchaysuyo (2012). Estos sitios corresponderían a propiedades o palacios "privados" de los gobernantes Incas y antecederían al advenimiento del sistema imperial Inca de grandes centros administrativos que sería desarrollado más tardíamente y, por ende, más lejos del área del nuclear del Cusco.

La construcción de este camino que unía Vilcashuaman y la Centinela, una ruta que unía la costa y la sierra, trajo consigo un cambió en las dinámicas geopolíticas regionales de la costa, reformulando el balance político de la región e incorporándola al imperio Inca.

Este camino, con notoria intervención Inca, tanto a nivel de los sitios como en el paisaje en general (andenes, cursos de agua, etc.), no dejó de ser utilizado a la caída del sistema imperial que le dio vida. Incluso después de la llegada de los españoles este tramo de camino jugó un rol en las relaciones políticas de los conquistadores con la población local (Barraza 2013:5).
$\mathrm{Y}$ asimismo fue acordado por Almagro, y por aquellos caballeros que allí juntos estaban, que se fuesen luego a Guaytara, que era fuerte, y se tornaría otra vez a intentar la paz. E dejado en aquel poblado de Zangalla al tesorero Alonso Riquelme con el tesoro del rey, y a dos alcaldes e regidores y otros algunos españoles, se partió con los demás gente de su campo e se fue a los aposentos de Guaytara, adonde asentó su real... (Cieza de León 1985:96).

Las guerras entre Francisco Pizarro y Diego de Almagro tuvieron como teatro de operaciones este camino que recorre el Valle de Pisco y que evidentemente seguía teniendo importancia y constituía una puerta a la capital del Tahuantinsuyo. La reutilización de la ruta y la leva que los conquistadores hacían de las poblaciones indígenas para sus batallas terminó por despoblar el área.

Pero este eje de movimiento entre costa y sierra, utilizando el valle de Pisco, continuó teniendo importancia en nuestra historia incluso en tiempos contemporáneos. Por ejemplo, la expedición libertadora de Álvarez de Arenales comenzó su campaña de la sierra subiendo de Pisco a Vilcashuamán, si bien no tomó exactamente el mismo camino, siguió el mismo eje de movimiento. Actualmente, la carretera nacional Libertadores-Wari, una de las principales vías de comunicación costa-sierra en el sur del Perú, corre paralela al camino incaico, lo que atestigua su vigencia.

Similares usos tempranos del camino por parte de los primeros europeos para adentrase en los territorios andinos han sido documentados en otras partes del continente, en particular en el sur donde se han realizados intentos para reconstruir la ruta seguida por Diego Almagro en su avance a la frontera sur (Bárcena 2017; Vitry 2007b). Esta evidencia sugiere que inicialmente las rutas fueron respetadas durante los primeros años que antecedieron a la dominación colonial propiamente dicha.

Otros ejemplos complementarios, que nos dan indicios de la continuidad histórica de estas rutas y la continuidad en los ejes de movimiento, se pueden ver inclusive en momentos más tardíos. Siguiendo como ejercicio el derrotero de los movimientos indígenas del siglo XVIII, como por ejemplo el de los Hermanos Angulo, vemos que estos tienden a seguir la misma ruta que tuvieron los Caminos Incas. Tratando de unir las zonas alrededor del Cuzco con la zona del Titicaca, como en tiempos prehispánicos, sugiriendo que en la mente de los rebeldes se mantenían percepciones del territorio rastreables a tiempos prehispánicos.

A raíz de los preparativos del Bicentenario y como parte de la revaloración de los actores locales en el proceso independentista, en el año 2014 se aprovechó para revalorar el rol del movimiento de los Hermanos 


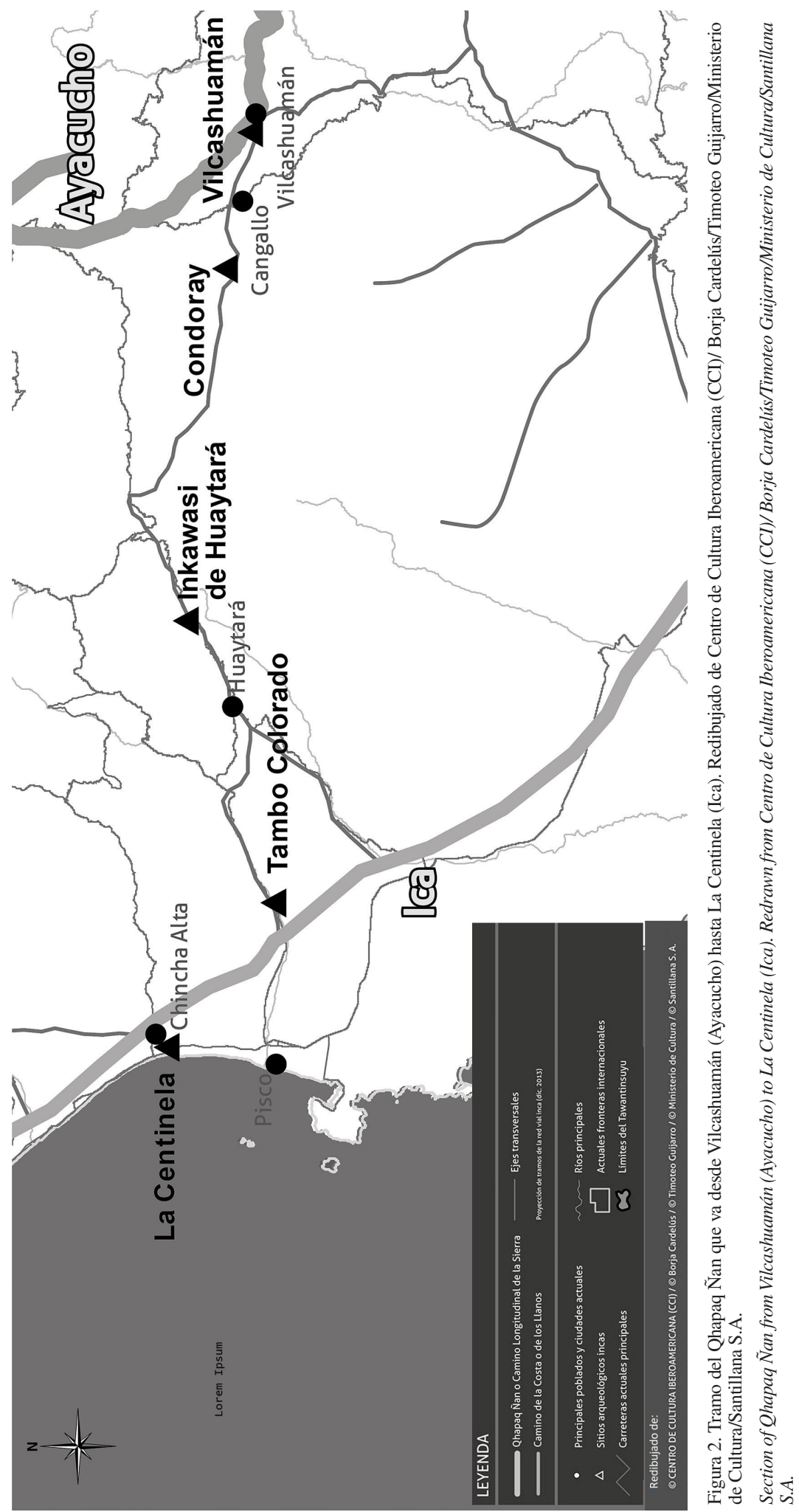



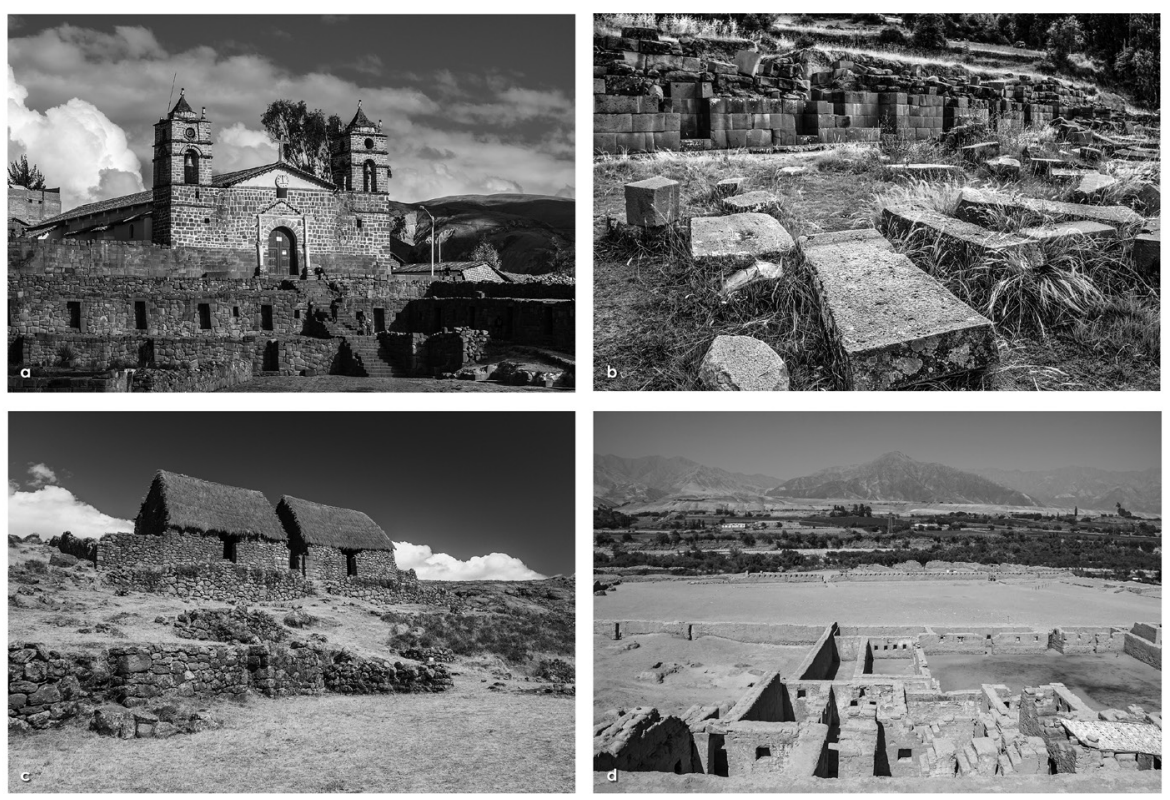

Figura 3. Sitios principales que se encuentran a lo largo del tramo Vilcashuamán-La Centinela: (a) Vilcashuamán, (b) Pomacocha, (c) Incahuasi de Huaytará y (d) Tambo Colorado.

Main sites located along the Vilcashuamán-La Centinela stretch: (a) Vilcashuamán, (b) Pomacocha, (c) Incahuasi de Huaytará and (d) Tambo Colorado.

Angulo y de Mateo Pumacahua. El movimiento de naturaleza local y popular, en su mayoría, empezó en la actual región del Cusco y se extendió a las áreas vecinas de Ayacucho y Puno para finalmente proseguir hasta el alto Perú (Bolivia). A la hora de mapear el movimiento de las tropas rebeldes se ve una correspondencia entre este movimiento y los ejes de Camino Inca registrados por el Proyecto Qhapaq Ñan para la zona.

Estas rebeliones se movieron en el espacio siguiendo básicamente los mismos ejes que había seguido la expansión Inca, tomando los mismos puntos geopolíticos de importancia y usando los mismos ejes de este movimiento, como son Ayacucho y el altiplano (Figuras 4 y 5). Una columna sale del Cusco siguiendo el camino del Chinchaysuyo para llegar al área de Ayacucho-Vilcas Huamán, desde donde pretendió seguir por el eje del Qhapaq Nan a la sierra norte. La otra columna siguió por el camino del Collasuyo y una tercera columna se dirigió a Arequipa, sin mayor éxito. Más allá del resultado de la revuelta o el impacto que tuvo finalmente, las rebeliones nos muestran que los procesos independentistas no fueron autónomos del territorio donde se desarrollan, sino que están intrínsecamente embebidos en ellos. Este ejercicio nos ayudó a revalorar el rol local e indígena en un proceso que la historia oficial define como criollo.

\section{La discontinuidad de rutas}

Sin embargo, también hay ejemplos de la discontinuidad de rutas, como en la región de Piura. Estos cambios no se dieron necesariamente de golpe o se derrumbaron como castillos de naipes (Martínez 2009:29), sino que se fueron dando a medida que el sistema colonial español se instauraba y una nueva ideología estatal se instalaba, trayendo profundos cambios culturales.

Al poco tiempo de desembarcar en Tumbes, al norte del Perú y en su camino hacia el sur, Francisco Pizarro fundó la ciudad de San Miguel de Piura en 1534, el cual en realidad fue el segundo intento de fundación de esta ciudad en lo que había sido un centro con ocupación prehispánica (Astuhuamán 2004). El asentamiento estaba vinculado a la Red Vial Inca y tuvo mucha importancia en los primeros años de la colonia hasta 1578 .

Astuhuamán (2004) propone un dramático colapso de San Miguel de Piura. Sostiene que sucedió en parte por la presencia de un fenómeno del Niño que impuso nuevas constricciones climáticas con las que los españoles no supieron lidiar. También señala que otra razón, tan o más importante, fue el advenimiento del sistema colonial bajo el Virrey Toledo y el sistema de reducciones que contribuyó a la pérdida del prestigio del sitio (Astuhuamán 2004). 


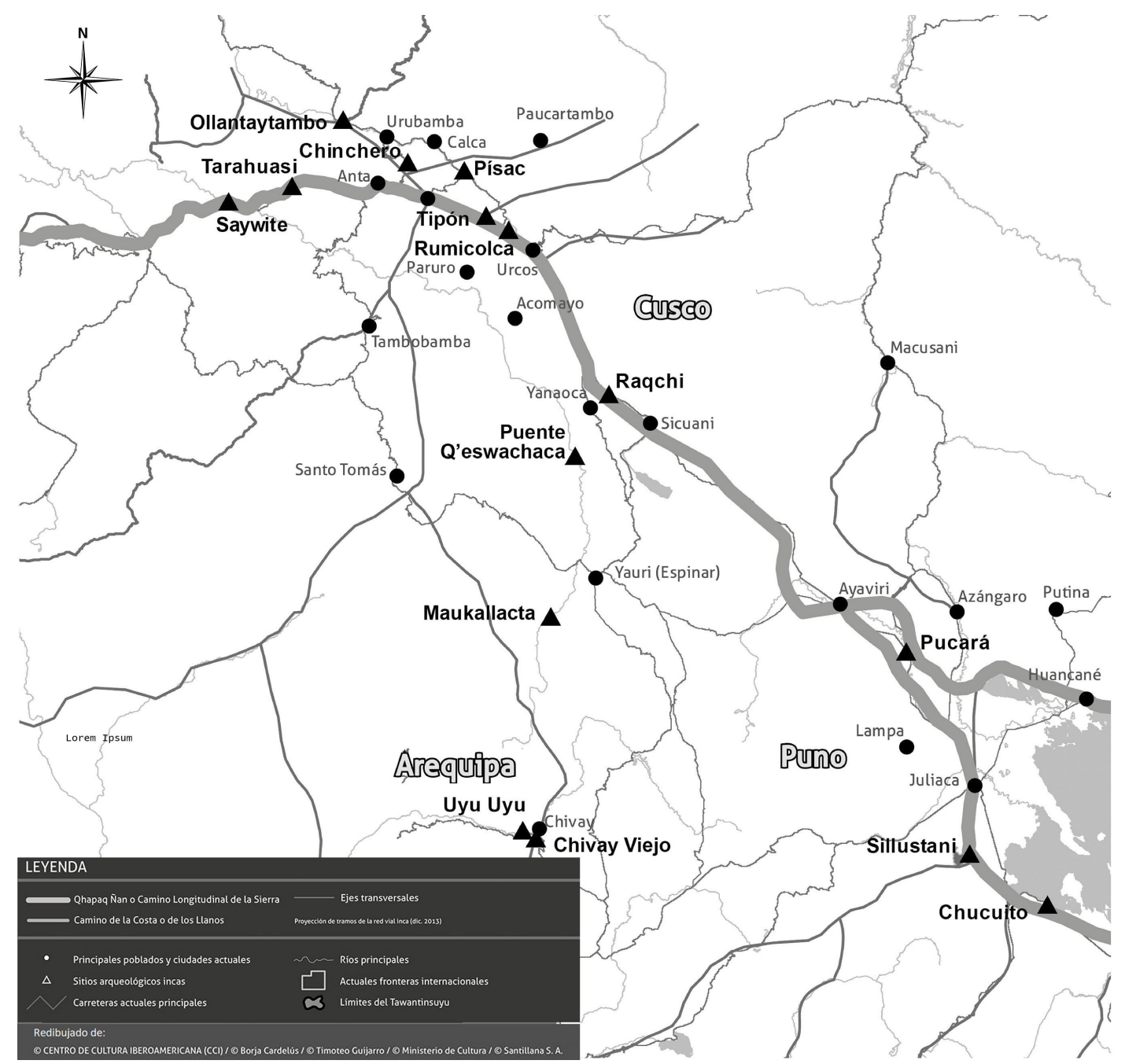

Figura 4. Ejes de movimiento de las tropas de los Hermanos Angulo y de Mateo Pumacahua sobrepuestas al Qhapaq Nan. Redibujado de Centro de Cultura Iberoamericana (CCI)/ Borja Cardelús/Timoteo Guijarro/Ministerio de Cultura/Santillana S.A.

Movement axes of the Angulo Brothers' and Mateo Pumacahua's troops overlapping the Qhapaq Ñan. Redrawn from Centro de Cultura Iberoamericana (CCI)/ Borja Cardelús/Timoteo Guijarro/Ministerio de Cultura/Santillana S.A.

El abandono de San Miguel de Piura o Piura la Vieja representa un movimiento en la ruta y eje de comunicación. Esta se desvió hacia la costa, en relación a lo que ahora es el Puerto de Paita (Figura 6), que fue el asentimiento principal en la zona hasta 1588 , cuando los inclementes ataques de piratas y corsarios obligaron a que la ciudad se retire hacia su ubicación actual.

Para mí, el caso de Piura representa la historia de como inicialmente los europeos usaron los caminos prehispánicos para entrar en los Andes hasta el advenimiento del sistema estatal colonial. El sistema colonial intentó reorganizar el territorio de acuerdo a sus ideas, pero lo resultante es fruto tanto del paisaje existente como de la nueva ideología en acción.

Inclusive, es posible encontrar ejemplos donde el Qhapaq Ñan pierde fuerza ante la llegada de las nuevas ideas económicas, paradigmas políticos y símbolos culturales. Estos tramos pierden el favor de las "ideologías" estatales. Al perder presencia en el Estado son progresivamente reemplazados por nuevos caminos o rutas. Sin embargo, a pesar de este abandono formal el camino mantuvo su uso cotidiano hasta el presente, por ejemplo, en el caso de Huachis en Ancash. 


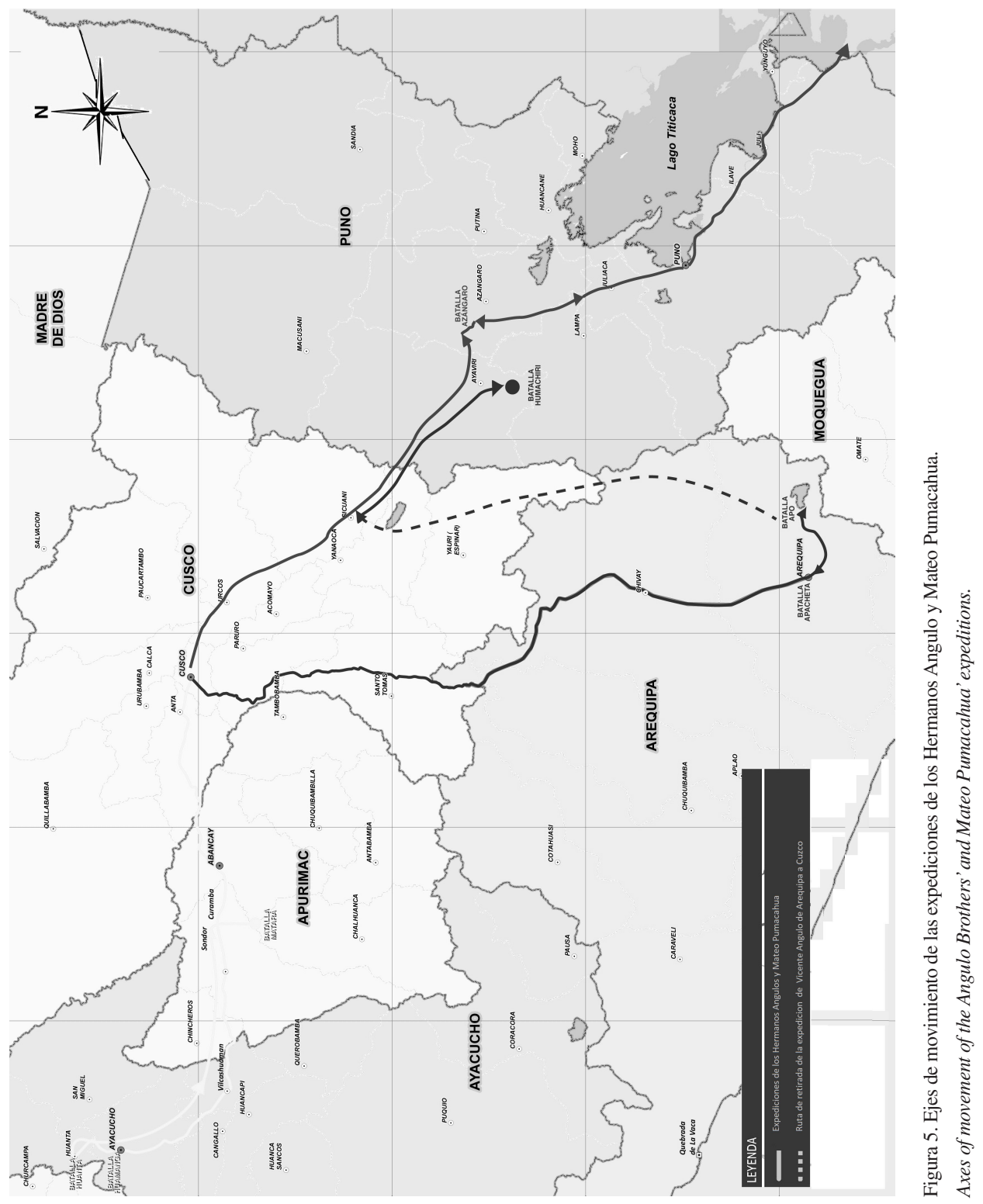




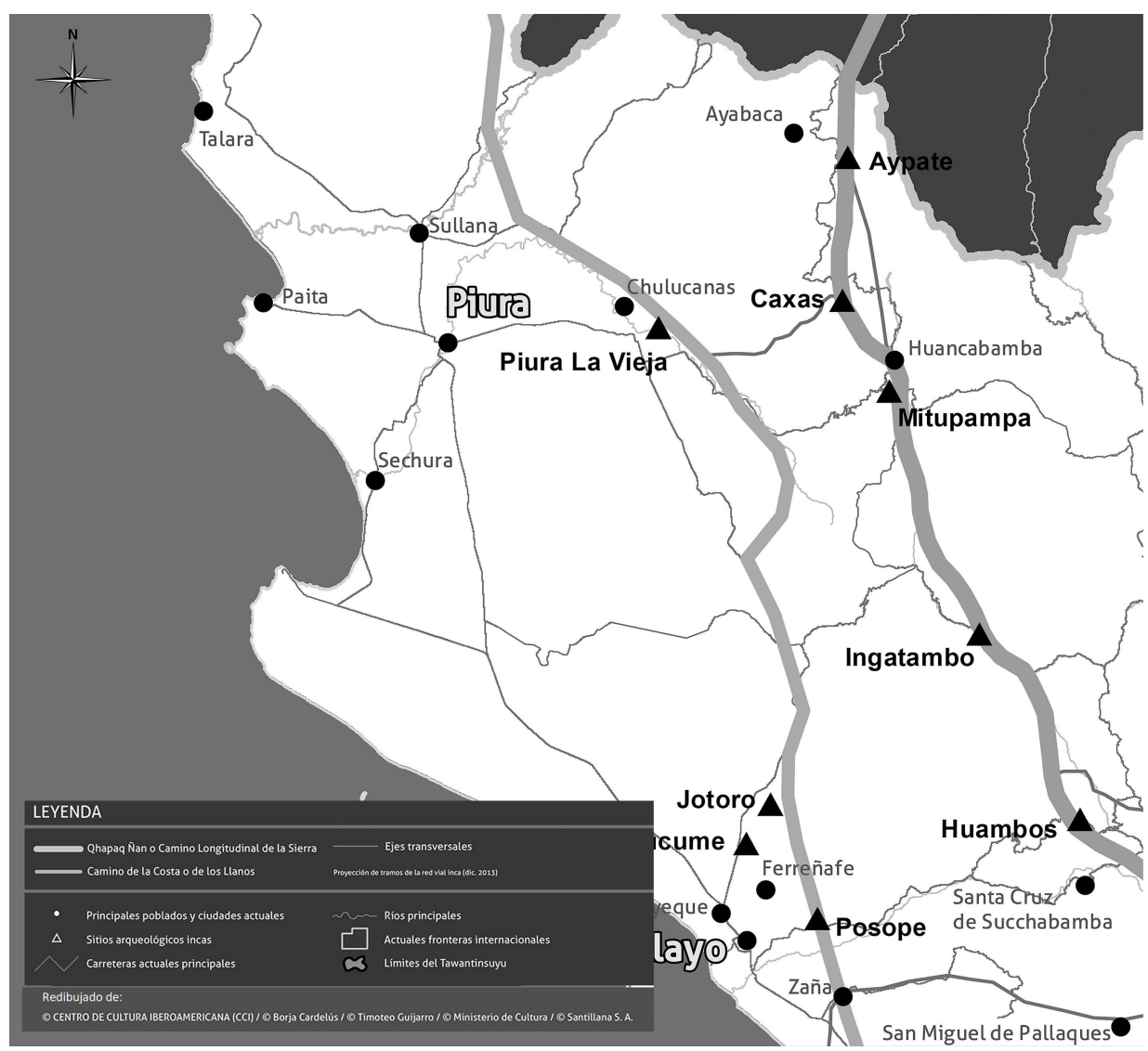

Figura 6. Ejes de movimiento en la zona de Piura. Redibujado de Centro de Cultura Iberoamericana (CCI)/ Borja Cardelús/ Timoteo Guijarro/Ministerio de Cultura/Santillana S.A.

Movement axes in the Piura area. Redrawn from Centro de Cultura Iberoamericana (CCI)/ Borja Cardelús/Timoteo Guijarro/Ministerio de Cultura/Santillana S.A.

Huachis queda en el Qhapaq Ñan propiamente dicho, o camino principal Inca, que en este tramo unió los sitios administrativos de Huánuco Pampa y Huamachuco (Figura 7). A la caída del Imperio Inca estos dos sitios perdieron importancia a nivel regional, mas no en la arena local. El camino que los unía fue perdiendo fuerza, en parte por la prioridad económica y geopolítica puesta por el nuevo régimen en el contacto costa-sierra. Esto ocasionó que rutas como Huamachuco-Trujillo crecieran en importancia (Topic y Topic 1993) y la fundación de una reducción en Huaraz en 1574 fuera cambiando el eje de movimiento al callejón de Huaylas sobre caminos secundarios de la red vial Inca (Bernabé 2007). La ruta principal se cambió del callejón de Conchucos al callejón de Huaylas, que resultaba más fácil de comunicar con la costa. Aunque a nivel local continuó teniendo un uso importante hasta nuestros días, comunicando a las distintas comunidades que se encuentran en esta ruta. El uso cotidiano mantuvo esta ruta, a pesar de su caída dentro del esquema mayor de la economía política.
Los pueblos en el camino quedaron de pronto alejados del Estado colonial y el Estado peruano hasta recientemente, donde se está revalorando este tramo por las nuevas explotaciones mineras. Sin embargo, pese al olvido del Estado, estos caminos siguieron comunicando a las poblaciones y comunidades de esta zona de la sierra peruana, la ruta continúa teniendo contenidos e importancia a nivel local, especialmente frente a un Estado ausente e ineficiente.

En estos tres ejemplos principales expuestos líneas arriba, la ruta de Vilcashuaman a Pisco, los caminos de Piura y el tramo Huaylas-Conchuchos, vemos las interacciones de los diversos factores que condicionan o favorecen la permanencia de rutas. En el caso del camino que lleva de Vilcashuaman hacia la costa, creemos que la influencia del paisaje jugó en su supervivencia. Esta ruta, que probablemente tenga un origen pre-Inca, utiliza el valle costeño de Pisco como eje de movimiento, el cual es un corredor "natural" para unir la costa y la sierra. Junto con la larga tradición cultural de este tramo del camino, que 


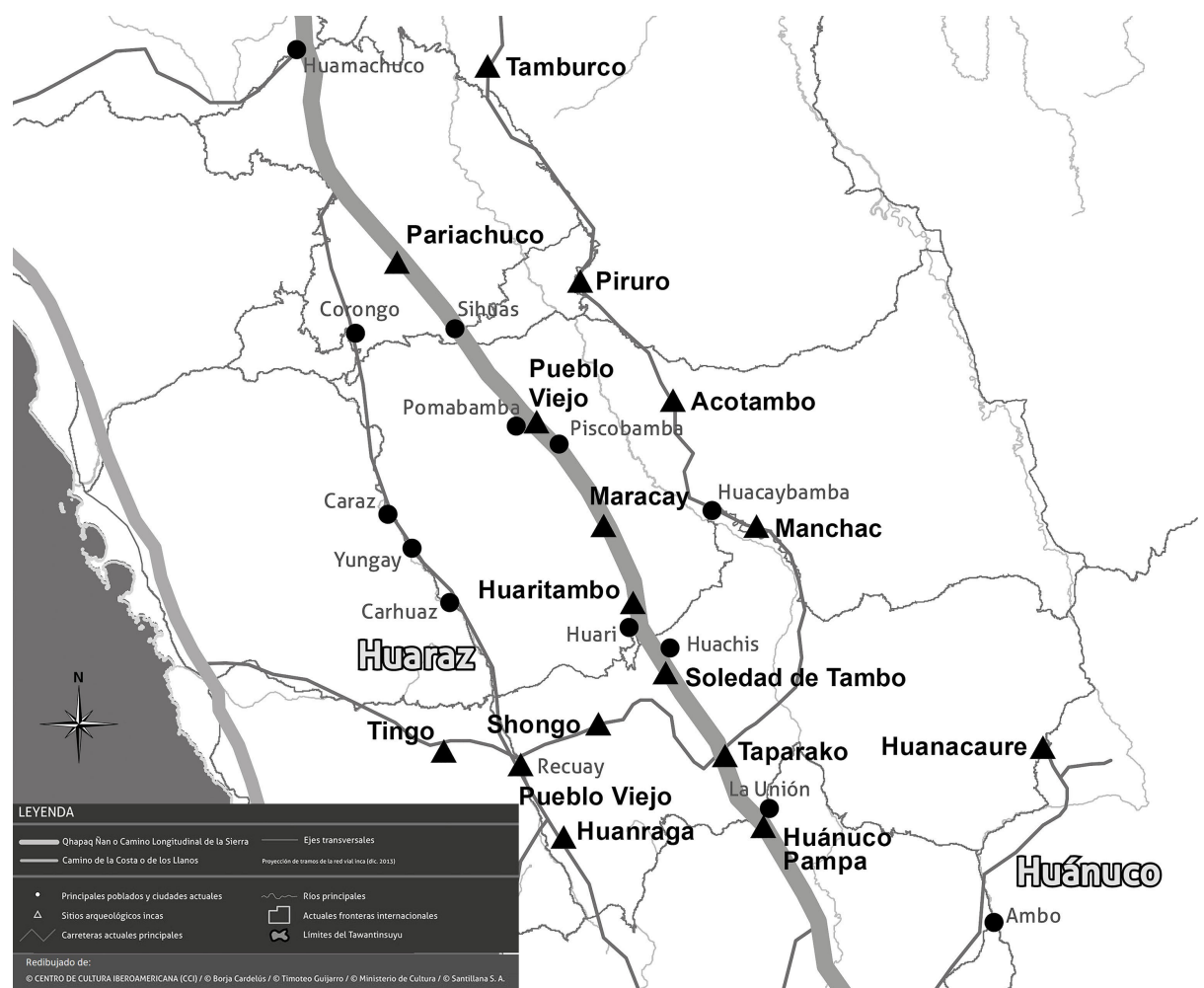

Figura 7. Ejes de movimiento en la zona de Huachis en Ancash. Redibujado de Centro de Cultura Iberoamericana (CCI)/Borja Cardelús/ Timoteo Guijarro/Ministerio de Cultura/Santillana S.A.

Movement axes in the Huachis area in Ancash. Redrawn from Centro de Cultura Iberoamericana (CCI)/Borja Cardelús/Timoteo Guijarro/Ministerio de Cultura/Santillana S.A.

tiene a Vilcashuaman como centro y eje, una serie de relaciones de larga data se entremezclan para mantener la vigencia de esta ruta.

En el caso de Huachis y Huaylas vemos justamente que dentro de las posibilidades condicionadas que presenta la geografía agreste de altura de la cordillera para establecer nuevas rutas, son las agendas económicas y políticas de los conquistadores las que priorizan determinadas rutas sobre otras. Pero el uso diario de la ruta mantiene en vigencia el tramo de Huachis pese a que es progresivamente borrada de la red formal.

Por último, en el caso de Piura, donde la geografía plana facilita las posibilidades de variación de las rutas, el Camino Inca parece ser más el resultado de una construcción imperial en la zona sin la larga tradición de otras áreas. La ruta es transformada continuamente de acuerdo a las necesidades de las nuevas administraciones políticas.

\section{Rompiendo con los Sitios, pero manteniendo las Rutas}

¿Cómo es posible la sobrevivencia y uso del camino si se supone que cuando los Incas cayeron se derrumbó con ellos su sistema administrativo y por ende su sistema vial?
Uno de los problemas que tiene tradicionalmente la arqueología peruana es la sobre importancia que se le da al sitio arqueológico. El sitio es dominante en nuestras investigaciones, muchas veces dejando al medio ambiente de lado. El interpretar los caminos desde una dependencia de los sitios arqueológicos hace que se entienda los caminos como una red donde los sitios arqueológicos son los nodos y los caminos los enlaces. Los caminos solo tendrían importancia en la medida que facilitaban la interacción, el flujo de información y el intercambio entre los nodos/sitios. Ya desde los trabajos pioneros de Alberto Regal (1936) y de John Hyslop (1984), el Camino Inca fue entendido como el articulador de un sistema administrativo jerárquico de sitios que incluía centros administrativos y tambos; los cuales eran las estructuras imperiales que permitieron una adecuada administración del área estatal. La concentración en el estudio de los "sitios" hizo que la investigación se centrara en entender los "nodos" de la red y su relación entre ellos. Este planteamiento engranaba perfectamente con la arqueología imperante a fines del siglo pasado, donde las visiones de los imperios y estados expansivos estaban contenidas en la lógica administrativa del flujo de información. Esta visión "administrativa" de las relaciones sociales entre los Incas y otras sociedades andinas era favorecida 
en la concepción de la red vial en términos de una construcción lineal, jerárquica y estática de centro provincial, tambo.

En los últimos años se han incrementado de manera progresiva los estudios que explícitamente adoptan al paisaje como el marco referencial sobre el cual entender los fenómenos históricos en tiempos Incas (Acuto 2012; Christie 2008; Farrington 1992; Julien 2012; Kaulicke et al. 2003; Kosiba y Bauer 2013; Vitry 2003; Wernke 2007). En estas ideas el paisaje no es solo un agente pasivo en el que se dan los hechos, sino que adquiere una dimensión adicional, la de agente activo en la formación de fenómenos sociales como el de Imperios o Estados expansivos.

Es así como, progresivamente, hemos entendido con mayor precisión que la geografía jugó un rol primordial en la forma que toman las relaciones sociales, políticas, culturales y económicas en el Perú pre y post colonial (Farrington 1992; Kaulicke et al. 2003). Cerros, rocas, fuentes de agua y ríos no son solo accidentes geográficos, sino elementos constituyentes de la relación del hombre con su entorno, la cual está totalmente integrada formando parte de las ideas del hombre andino.

La adopción de marcos conceptuales como paisaje o territorio rompe la sobre dependencia en los sitios. Los grandes sitios administrativos quedan en segundo plano, la ocupación humana se ve en escalas temporales mayores y se hace más visible la evidencia de la ocupación local. Empezamos a entender ahora que los caminos sobreviven los Estados que los construyen porque son legitimados en su uso cotidiano. Por ello, es necesario romper con la división temporal entre pasado hispánico y prehispánico que ha dominado la discusión histórica del área andina.

Pero hay que tener cuidado de no irnos hacia el otro extremo, la tentación de la aproximación desde el paisaje y el territorio es la de ignorar el cambio. Como hemos visto, si bien se reconoce que muchas de estas rutas usadas por los Incas son de origen anterior (Martínez 2009:29), sería un error pensar que estas rutas no sufrieron potenciales cambios. Schreiber (1987) y Williams (2017) plantean que si bien las redes viales en épocas Wari y Tiahuanaco sentaron las bases para el Qhapaq Nan, por otro lado fueron muy distintas (Williams 2017:31).

\section{Una historia de quiebres y negaciones}

Como hemos sostenido, el impacto del hombre en el paisaje sienta las bases para los siguientes desarrollos sociales y culturales. Sin embargo, la historiografía oficial del Perú se ha construido priorizando quiebres y no continuidades (Vega Centeno 2017). En una secuencia lineal de carácter evolutivo, la historia oficial nos habla de un pasado prehispánico interrumpido por la llegada de los españoles. Este fenómeno exógeno trajo consigo cambios en la naturaleza y forma de las relaciones sociales, políticas y económicas en la región, generando una nueva realidad engranada en los sistemas coloniales de Occidente. En esta narrativa, la cultura original fue virtualmente desaparecida, dejando solo algunos remanentes de pasadas grandezas. El resultado de este quiebre fue la Colonia. Del mismo modo, el fin de ese periodo y de la presencia de España en América fueron tomados como una ruptura de nuestro proceso histórico. Un nuevo proceso exógeno que trajo importantes transformaciones culturales y sociales, donde se retira el peninsular para dar paso al criollo, quien finalmente es el legítimo habitante de este territorio al ser heredero de los Incas, pero al mismo tiempo de la modernidad (Marcone 2011).

Esta narrativa que privilegia los quiebres niega la existencia de un proceso de larga duración y supedita nuestro proceso histórico a eventos externos a nuestra sociedad (ya sea la conquista o las corrientes libertadoras), permitiendo enajenar a la gente de su historia y reduciendo el pasado a esquemas excluyentes que se resumen en el título del famoso artículo de Cecilia Méndez (1996): "Incas sí, indios no".

\section{Discusión}

En los Andes, las características del paisaje fueron determinantes para el establecimiento de los tramos de camino. Como sugerimos líneas arriba, creemos que la geografía generó que la variabilidad de las rutas fuera relativamente baja y facilitó la preservación de muchas de ellas a pesar de los cambios políticos, económicos o sociales que sucedieron durante 5.000 años de historia. Estas características, tanto en su dimensión cultural como natural, parecen haber sido una consideración principal en el diseño de las rutas en la época colonial. Esto habría obligado a los europeos a mantener, al menos al principio, el sistema de las mismas rutas. Posteriormente, con la llegada e instauración del sistema Colonial propiamente dicho, estas rutas empezaron un largo proceso de modificación que siguió por toda nuestra historia.

Algunas rutas cambiaron, como la de Huachis, hubo una reformulación de algunos de los ejes de movimiento que trajo parcialmente el desuso y la reformulación de algunos de los tramos. Otras, como la de Piura, simplemente cayeron en desuso por falta de la validación que finalmente les da el uso diario y local de las mismas. Mientras que muchas otras rutas, especialmente en zonas de mayor población, con evidencia de mayor complejidad social y política y larga trayectoria cultural, se mantuvieron casi sin intervención hasta el presente, como en el caso del tramo Vilcashuaman - Chincha.

Proponemos -a manera de hipótesis- que la primera aproximación de los españoles a la región andina, así como las primeras interacciones con las poblaciones 
locales, se dio sobre la vera del camino prehispánico. La conquista se hizo a través de los caminos, como Víctor Von Hagen (1952:5) señalaba: "el Perú fue traicionado por sus caminos" (1952:5). No es sino hasta cuando empieza a funcionar plenamente el sistema colonial estatal cuando se inicia la variación de las rutas. La nueva ideología estatal -entendida como los modelos económicos, políticos y sociales que llegaron dentro de la experiencia colonial española- priorizó la costa, probablemente por sus necesidades de comunicación con la metrópoli. Esta necesidad se impuso pese a los usos cotidianos del camino, generando una tensión entre las estructuras políticas y la práctica diaria del camino presente hasta nuestros días.

\section{Conclusiones}

El presente trabajo es un intento inicial de entender la construcción de los caminos en el Perú desde una perspectiva de paisaje y territorio. Esta permite estudiar los caminos en una escala temporal amplia donde la historia de estos caminos es el reflejo de la historia del hombre actuando en el paisaje.

Los ejemplos expuestos son aún generales y tienen una escala de análisis todavía gruesa, pero sirven para graficar los principales supuestos teóricos sobre los que se viene armando una investigación para recuperar el desarrollo de los caminos y sus repercusiones culturales y sociales. Donde los cambios en el trazo, pero especialmente en las rutas, nos cuentan una historia de cambio social y cultural dentro de un mismo territorio.

El Qhapaq Ñan visto desde una perspectiva de territorio nos brinda una visión temporal mayor y una escala espacial amplia, mostrando como el camino es efectivamente el enlace entre procesos sociales que usualmente se conceptualizan como separados. La práctica cotidiana le permitió al camino sobrevivir parcialmente los cambios políticos sucedidos después de 1531 y dejar su impronta en las trasformaciones sociales coloniales y posteriormente republicanas, aunque no de la misma manera ni con los mismos contenidos.

Si los ejemplos aquí mostrados indican algo, es que los caminos estudiados en escalas espaciales y temporales amplias nos permiten entender como el paisaje es una arena más donde los diversos segmentos de la sociedad negocian o compiten. La ideología estatal española tuvo que incorporar parcialmente las prácticas y costumbres de los pobladores locales, asi como los pobladores locales reformularon sus ejes de movimiento y su territorio.

Estas visiones nos permiten acercarnos a entender la compleja relación de cambio y continuidad que existió a través de la historia en el territorio peruano para finalmente discutir los impactos negativos y excluyentes que tuvo la construcción de la historia peruana al dar más peso a los cambios que a las continuidades.

Agradecimientos: Quiero agradecer a mis compañeros del Proyecto Qhapaq Ñan - Sede Nacional Perú, con quienes trabajé entre el 2012- 2018, por la permanente alimentación académica y desafío intelectual, en especial a Gabriela García Benavente por su ayuda en la edición y preparación de este manuscrito. Asimismo, gracias a los revisores por los comentarios realizados a esta contribución.

\section{Referencias Citadas}

Acuto, F. 2012. Landscapes of Inequality, Spectacle and Control: Inka Social Order in Provincial Context. Revista de Antropología 25:9-64.

Altschuler, B. 2013. Territorio y desarrollo: aportes de la geografía y otras disciplinas para repensarlos. Theomai 27-28:64-79.

Ashmore, W. 2005. Lived experiences of space, time and cosmovision. Cambridge Archaeological Journal 25 (1):293-297.

Astuhuamán, C. 2016. Fundación, esplendor y colapso de la iglesia de San Miguel de Piura (1534-1578), primer templo del Perú. Boletín de Arqueología PUCP 21:39-56.

Bárcena, J. 2017. Los pasos andinos de la Rioja (Argentina): La dominación Inca y el derrotero de Diego de Almagro. Boletín del Museo Chileno de Arte Precolombino 22 (2):153-179.

Barraza, S. 2013. Desplazamientos Hispanos por el Qhapaq Nan y Abandono de Asentamientos Incas durante el Período Colonial Temprano: el Caso de Huaytará. Ministerio de Cultura, Lima.

Bernabé, J. 2014. La Ruta Inca a los Huaylas-El Qhapaq Ñan entre Conococha y Recuay. Ministerio de Cultura, Lima.

Cardelús, B. y T. Guijarro 2013. Cápac Ñan. El Gran Camino Inca. Aguilar, Lima.
Casaverde, G. 2017. Definiendo la cronología relativa en los caminos: el camino del Pariacaca. Boletín del Museo Chileno de Arte Precolombino 22 (2):65-81.

Cieza de León, P. 1985. Obras Completas II. Las Guerras civiles Peruanas Consejo Superior de Investigaciones Científicas, Instituto Gonzalo Fernando de Oviedo, Madrid.

Chacaltana, S, E. Arkush y G. Marcone (eds.) 2017. Nuevas Tendencias en el Estudio de los Caminos. Ministerio de Cultura, Proyecto Qhapaq Nan, Lima.

Chacaltana Cortez, S., y G. Cogorno Ventura 2018. Arqueología Hidráulica Prehispánica del Valle Bajo del Rímac (Lima, Perú): Estudio de un Sistema de Riego Costeño. Instituto Riva Agüero, Lima.

Christie, J. 2008. Inka Roads, Lines, and Rock Shrines: A Discussion of the Contexts of Trail Markers. Journal of Anthropological Research 64 (1):41-66.

Dalakoglou, D. y P. Harvey 2012. Roads and anthropology: ethnographic perspectives on space, time and (im)mobility. Mobilities 7 (4):459-465.

Delgado Berrocal, S. 2019. Paisajes de altura: Los andenes del distrito de Cabana, Valle del Sondondo, Perú. Proyecto, Progreso, Arquitectura 21:72-92. 
Farrington, I. 1992. Ritual geography, settlement patterns and the characterization of the provinces of the Inka heartland. World Archaeology 23 (3):368-385.

Garrido, F. 2016. Rethinking imperial infrastructure: A bottomup perspective on the Inca Road. Journal of Anthropological Archaeology 43:94-109.

Garrido, F. y D. Salazar 2017. Imperial Expansion and Local Agency: A Case Study of Labor Organization Under Inca Rule. American Anthropologist 119 (4):631-644.

González Godoy, C. 2017. Arqueología vial del Qhapaq Ñan en Sudamérica: Análisis teórico, conceptos y definiciones. Boletín del Museo Chileno de Arte Precolombino 22 (1):15-34.

González Navarro, C. 2012. Una aproximación al Territorio Indígena Prehispánico, Córdova (Siglo XVI). Andes 23 (1):1-29.

Hyslop, J. 1984. The Inka Road System. Academic Press, Orlando.

Julien, C. 2012. The Chinchaysuyu Road and the Defenition of an Inca Imperial Landscape. En Highways, Byways, and Road System in the Pre-Modern World, editado por S.E. Alcock, J. Bodel y R.J.A. Talbert, pp. 147-167, John Wiley and Sons, Chichester.

Kaulicke, P., R. Kondo, T. Kasuda y J. Zapata 2003. Agua, Ancestros y Arqueología del paisaje. Boletín de Arqueología PUCP 7:27-57.

Kosiba, S. y A. M. Bauer 2013. Mapeando el paisaje político: un análisis SIG de las diferencias medioambientales y sociales. Cuadernos del Qhapaq Ñan 1 (2):120-160.

Lamana, G. 2008. Domination without Dominance: Inca-Spanish Encounters in Early Colonial Peru. Duke University Press, Durham.

Larkin, B. 2013. The politics and poetics of infrastructure. Annual Review of Anthropology 42:327-343.

Lumbreras, L.G. 1990. Los Andes antes de 1532. En Los Andes: el Camino del Retorno, editado por H. Bonilla, L.G. Lumbreras, A. Menéndez-Carrión, G. Ramón y E. Tandeter, pp. 21-25. FLACSO Sede Ecuador, Quito.

Masquelier, A. 2002. Road mythographies: space, mobility, and the historical imagination in postcolonial Niger. American Ethnologist 29 (4):829-856.

Marcone, G. 2011. Más Inca que los Incas. Cuaderno de Investigación del Archivo Tello \#8. Lima, Museo de Arqueología y Antropología de la Universidad Nacional Mayor de San Marcos.

Martínez, G. 2009. Qhapaq Ñan: El Camino Inca y las transformaciones territoriales en los Andes peruanos. Ería 78-79:21-38.

Martínez, M.A.N. y J.A. Morillo 2015. El Qhapaq Ñan, camino principal andino: patrimonio cultural de la humanidad de Argentina, Bolivia, Chile, Colombia, Ecuador y Perú. Novum Otium 1 (1):11-22.

Mendez, C. 1996. Incas sí, indios no: Notes on Peruvian creole nationalism and its contemporary crisis. Journal of Latin American Studies 28 (1):197-225.

Murra, J.V. 2002. El Mundo Andino: Población, Medio Ambiente y Economía, Fondo Editorial PUCP, Lima.

Pino Matos, J. 2017. Wamani: territorialidad, autoridades ancestrales y redes de parentesco sagrado en el Tawantinsuyu. Reflexiones y propuestas sobre la supuesta organización provincial Inca. En Repensar el Antiguo Perú. Aportes desde la Arqueología, editado por R. VegaCenteno Sara-Lafosse, pp. 441-552. Fondo Editorial PUCP, IEP, Lima.
Regal, A. 1936. Los Caminos del Inka en el Antiguo Perú. Sanmartí y Cía. Lima.

Ruiz, R., F. Rodríguez y J. Coronado 2015. Exploring landscapes through modern roads: historic transport corridors in Spain. Landscapes 16 (1):44-62.

Schreiber, K.J. 1987. Conquest and consolidation: a comparison of the Wari and Inka occupations of a highland Peruvian valley. American Antiquity 52 (2):266-284.

Snead, J.E., C.L. Erickson y J.A. Darling (eds.) 2011. Landscapes of Movement: Trails, Paths, and Roads in Anthropological Perspective, vol. 1. University of Pennsylvania Press, ciudad?.

Topic, J. y T. Topic. 1993. A summary of the Inca occupation of Huamachuco. En Provincial Inca: Archaeological and Ethnohistorical Assessment of the Impact of the Inca State, editado por M.A. Malpass, pp. 17- 46. University of Iowa Press, Iowa.

Treacy, J. M. 1994. Las Chacras de Coporaque: Andenería y Riego en el Valle del Colca. Instituto de Estudios Peruanos, Lima.

VanValkenburgh, P. 2017. Unsettling time: Persistence and memory in Spanish colonial Peru. Journal of Archaeological Method and Theory 24 (1):117-148.

Vega-Centeno, R. 2017. Repensar el Antiguo Perú. Aportes desde la Arqueología. Fondo Editorial PUCP, IEP, Lima.

von Hagen, V.W. 1952. America's oldest roads. Scientific American $187(1): 17-21$.

Vitry, C. 2003. Control territorial a través de puestos de observación y peaje en el camino del Inca. Tramo Morohuasi- Incahuasi, SaltaArgentina. Cuadernos de la Facultad de Humanidades y Ciencias Sociales 20:151-172.

Vitry, C. 2007a. Caminos rituales y montañas sagradas. Estudio de la vialidad Inka en el nevado de Chañi, Argentina. Boletín del Museo Chileno de Arte Precolombino 12 (2):69-84.

Vitry, C. 2007b. La ruta de Diego de Almagro en el territorio argentino: un aporte desde la perspectiva de los caminos prehispánicos. Revista Escuela de Historia 6:325-360.

Watchel, N. 1973. Sociedad e Ideología. Ensayos de Historia y Antropología Andina. Instituto de Estudios Peruanos, Lima.

Wernke, S. 2007. Negotiating Community and Landscape in the Peruvian Andes: A Transconquest View. American Anthropologist 109 (1):130-152.

Wernke, S., G. Oré, C. Hernández, S. Norman, L. Kohut, L. Waller, V. Vylegzhanina y G. Marcone 2017. Ejes de articulación: análisis de la red espacial del Qhapaq Ñan en el sur del Perú. En Nuevas Tendencias en el Estudio de los Caminos, editado por S. Chacaltana, E. Arkush y G. Marcone, pp. 124-143. Ministerio de Cultura, Proyecto Qhapaq Nan, Lima.

Wernke, S.A. 2013. Negotiated Settlements: Andean Communities and Landscapes under Inka and Spanish Colonialism. University Press of Florida, Florida.

Williams, P.R. 2017. Una perspectiva comparada de Caminos Wari y Tiwanaku: los antecedentes del Qhapaq Nan Incaico. En Nuevas Tendencias en el Estudio de los Caminos, editado por S. Chacaltana, E. Arkush y G. Marcone, pp. 30-47. Ministerio de Cultura, Proyecto Qhapaq Ñan, Lima. 
